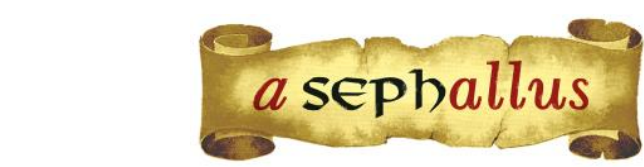

Revista aSEPHallus de Orientação Lacaniana

Núcleo Sephora de Pesquisa sobre o Moderno e o Contemporâneo

ISSN $1809-709 \mathrm{X}$

\title{
Desmentido ou inexistência do Outro: a era da pós-verdade ${ }^{1}$
}

Tania Coelho dos Santos

Pós-doutorado no Departamento de Psicanálise de Paris VIII (Paris, França) Professor Associado, nível IV no Programa de Pós-graduação em Teoria Psicanalítica/UFRJ (Rio de Janeiro, Brasil) Pesquisadora do CNPQ nível 1 C (Brasil) Presidente do Instituto Sephora de Ensino e Pesquisa de Orientação Lacaniana/ ISEPOL (Rio de Janeiro, Brasil) Psicanalista Membro da École de La Cause Freudienne, da Escola Brasileira de Psicanálise e da Associação Mundial de Psicanálise Membro da Associação Universitária de Pesquisa em Psicopatologia Fundamental

(Brasil)

E-mail: taniacs@openlink.com.br

Resumo: Não há fatos, somente interpretações. Esta tese foi inaugurada por Friedrich Nietzsche em $A$ Gaia Ciência. Talvez até pareça a muitos psicanalistas que seja de Lacan. Lacan é nietzchiano quando afirma que toda verdade é estrutura de ficção. Mas é freudiano quando defende que a verdade não é o real. O real não se deixa reduzir às nossas crenças, ficções, ideologias, sonhos e fantasias. E lanço ao nosso auditório a seguinte pergunta: é isso que a psicanálise nos ensina? Que a verdade se reduz ao ponto de vista de cada um? Não há nada de real, além do interesse de cada um. O grande Outro não existe? O que é o grande Outro lacaniano? É o reino da ficção, da verdade mentirosa, da fantasia e dos desmentidos? Ou existe uma razão no real?

Palavras-chave: verdade; pós-verdade; desmentido; real; Outro.

\section{Démenti et inexistence de l'Autre: l'ére le la post vérité}

Les faits n'éxistent pas, seulement les interpretations. Cette thèse a été inaugurée par Friedrich Nietzsche dans La Gaie Science. Beaucoup d'analystes, peut-être, croient que c'est de Lacan. Lacan est nietzschean quand il propose que toute verité a une structure fictionnelle. Mais, il est freudien quand il propose que la verité n'est pas le réel. Le réel ne se réduit pas à nos croyances, fictions, ideologies, rêves et fantaisies. Je pose à l'auditoire la question suivante: qu'est-ce-que la psychanalyse nous aprend-t-elle? Que la vérité se réduit au point de vue de chacun? Qu'il n'ya a rien qui soit réel, sauf l'interêt de chacun? Le grand Autre n'existe pas? Qu'est-ce que c'est que le grand Autre lacanien? Est-il le reine de la fiction, de la verité menteuse, de la fantaisie et des démenti? Où, existe-t-il une raison dans le réel?

Mots-clés: verité; post-vérité; démenti; réel; Autre.

\section{Denial and the Other inexistence: the post-truth era}

There are no facts, only interpretations. This thesis was inaugurated by Friedrich Nietzche in The Gay Science. Maybe many psychoanalysts believe that this belongs to Lacan. Lacan is nietzcheanian when he states that all the thruths are nothing but fiction. But, he is freudienian when he states that the truth is not the real. The real cannot be reduced to our believes, fictions, ideologies, dreams and fantasies. I propose to our auditory the following question: what does psychoanalysis teach us? The truth is nothing but the point of vue of each one of us? There is no real, only self-interest? The great Other does not exist? What is the great Other? Is it the realm of fiction, the lying truth, the fantasy and the denials? Or, is there reason in the real?

Keyword: truth; post-truth; denial; real; Other. 


\section{Desmentido ou inexistência do Outro: a era da pós-verdade}

\section{Tania Coelho dos Santos}

Não há fatos, somente interpretações. Esta tese foi inaugurada por Friedrich Nietzsche em A Gaia Ciência. Talvez até pareça a muitos psicanalistas que seja de Lacan. Lacan é nietzschiano quando afirma que toda verdade é estrutura de ficção. Mas é freudiano quando defende que a verdade não é o real. 0 real não se deixa reduzir às nossas crenças, ficções, ideologias, sonhos e fantasias.

O dicionário da Universidade de Oxford, inicialmente concebido em 1879, costuma atualizarse registrando as palavras desde a sua origem até os novos significados que elas adquirem graças ao uso corrente nas ruas. Pós verdade (Post-truth) é um adjetivo. Tem uma década mais ou menos. Define-se como algo que denota circunstâncias nas quais os fatos objetivos tem menos influência para definir a opinião pública do que o apelo à emoção ou às crenças pessoais". O jornalista Luiz Claudio Latgé (2016) observa que: "a verdade perdeu o valor. Não nos guiamos mais pelos fatos. Mas pelo que escolhemos ou queremos acreditar que é verdade".

Jill Lepore, professora de História na Harward Univeristy, em sua resenha sobre o livro do filósofo Michael P. Lynch intitulado "The internet of Us", publicada pelo New Yorker, em 21/3/2016, proclama a fim da era dos fatos e constata que na história da verdade, um novo capítulo começa:

E, então, surgiu a Internet. A era dos fatos está chegando ao seu fim: 0 lugar que outrora era ocupado por 'fatos' está sendo tomado por 'dados'. Isso consiste em um assassinato epistemológico, simplesmente porque o agrupamento e a ponderação de fatos requer uma investigação, um discernimento e um julgamento, enquanto $\mathrm{o}$ agrupamento e a análise de dados pode ser delegada a máquinas. "O principal conhecimento, hoje, é o 'Google-conhecimento' - conhecimento adquirido online", escreveu Lynch em "A Internet de Nós" (seu título é uma derivação do aclamado e desconcertante "A Internet das Coisas"). Hoje, nós raramente descobrimos fatos, observa Lynch. Ao invés disso, nós os 'downloadamos'. É claro, nós também os 'uploadlamos': com cada clique e cada movimento do teclado, arrancamos pequenas partes de nós mesmos e as entregamos ao Leviatã dos dados. (Lepore, 2016) ${ }^{2}$

Analistas políticos, por exemplo, vêm tentando entender a rápida ascensão de Donald Trump, candidato à presidência dos Estados Unidos e vêm concluindo que ele avança porque mente. De acordo com o Politico.com: "Suas observações representam uma mistura extraordinária de declarações imprecisas sobre política interna e externa e autoelogios pessoais e profissionais que raramente correspondem à verdade quando confrontados com as fontes primárias" (apud Carranca, 2016). 
De acordo com Tony Schwartz, ghost writer da biografia intitulada Trump: a arte da negociação (1988), mentir é para ele uma segunda natureza. Trump tem a capacidade de se convencer de que aquilo que estiver falando em um dado momento é verdade, ou quase, ou deveria ser. Ralph Keys (2004), diferentemente, toma o fenômeno no quadro histórico mais amplo e defende que entramos numa era da Pós-verdade em seu livro intitulado: The post-truth era: deshonesty and deception in contemporary life.

Em seu artigo intitulado Lula e Trump, José Padilha (14/08/2016) - conhecido cineasta compara a esquerda brasileira com os conservadores americanos, destacando que estes dois grupos, tão díspares ideologicamente, têm alguma coisa em comum: perderam a honestidade intelectual. A esquerda brasileira a perdeu porque se recusa a aceitar as incontestáveis evidências de que Lula e o PT operaram uma quadrilha que desviou bilhões de dólares dos cofres públicos. E os conservadores americanos porque se recusam a aceitar o fracasso da economia da oferta e apoiam as loucuras de Trump. Ambos os grupos, para defender suas posições, construíram narrativas fantasiosas, varrendo para debaixo do tapete os fatos que refutam suas ideias.

Ana Maria Machado (2016) destaca comportamentos de Lula muito parecidos com os de Trump. Ela afirma que a fanfarronice de Lula, por exemplo, quando declara à BBC de Londres que durante o seu governo o Brasil foi um país mais rico que a Inglaterra ou expressões como "nunca antes na história do Brasil...", conferem ao seu governo uma dimensão gloriosa, redentora. Com afirmações tais como: "não existe alma mais honesta que a minha", pretende equiparar sua trajetória à de Jesus Cristo. A seguinte declaração, por exemplo, é de um cinismo estarrecedor: "As pessoas achincalham muito a política. Mas a posição mais honesta é a do político, sabe porquê? Por que todo ano, por mais ladrão que ele seja, tem que ir para a rua, encarar o povo e pedir voto. O concursado se forma na universidade, faz um concurso e tá com o emprego garantido para o resto da vida"3.

No domingo de 11/09/2016, José Padilha - cineasta já mencionado acima - reproduz a seguinte declaração de Paul Krugman (prêmio Nobel de economia): "O que você realmente deve buscar em um mundo que sempre nos confronta com surpresas desagradáveis, é a integridade intelectual: predisposição para encarar os fatos, mesmo quando eles estão em desacordo com as suas ideais e a capacidade de admitir erros e de mudar de rumo".

Considero que este ponto de vista é também, estritamente, aquele que foi adotado por Freud como método. Acreditar na integridade intelectual que nos permitiria distinguir a verdade e a mentira tornou-se um sinal de ingenuidade? A psicanálise lacaniana nos ensina que ser é parecer e que "assim é, se lhe parece"? Ou será que é preciso distinguir a verdade do desejo - que abordamos numa análise - da verdade no sentido racional, científico ou intelectual?

Padilha (11/09/2016) prossegue citando Imre Lakatos, economista e pesquisador da London School of Economics, que defende que a honestidade intelectual não é uma questão filosoficamente abstrata, é uma questão de vida ou morte. Os debates acerca da honestidade intelectual, afirma este autor, concentram-se em duas questões. A primeira diz respeito à sua função social e evolutiva. 
A segunda me parece que seja de natureza psicológica: uma pessoa é intelectualmente honesta quando ela está disposta a abandonar as suas ideias caso fique demonstrado que elas são logicamente contraditórias ou incompatíveis com enunciados que se referem aos fatos. Nada menos que a razão científica.

E a verdade na arte da política? É o contrário da verdade na ciência? Reproduzo Renato Murad, leitor paulista de $O$ Globo:

Estranho buscar entender a política. Seria a arte de contrariar os fatos? Interpretar a verdades e até mesmo mentir? Atribuir a terceiros a culpa pelos fracassos e se apropriar das atividades que lograram êxito? Buscar realizações pessoais, incansavelmente? Fazer uso de incompetentes para manipulá-los? Ignorar os fundamentos da democracia? Efetuar discursos com emoção na tentativa de sugestionar despreparados? Conviver com delitos entendendo-os como normais na vida pública? Certamente que não. Embora seja o que entendi no pronunciamento de Lula em sua defesa, frente à fortes acusações que pairam sobre sua vida. (Murad, $18 / 09 / 2016)$

E lanço ao nosso auditório a seguinte pergunta: é isso que a psicanálise nos ensina? A regra que vale na política é o dito popular, "farinha pouca, meu pirão primeiro"? Que a verdade depende somente do ponto de vista ou dos interesses de cada um? Não há nada de real, além da verdade do interesse de cada um. Minha fala vai insistir no tema de nosso convidado deste ano, Dany-Robert Dufour. O grande Outro não existe? O que é o grande Outro lacaniano? É o reino da ficção, da verdade mentirosa, da fantasia e dos desmentidos? Ou existe uma razão no real?

Alguns psicanalistas radicalizam histericamente a hipótese de que o grande Outro não existe, que o Real é sem lei e não tem sentido. Não acho um bom método. Pois o que não tem sentido, é ainda assim uma estrutura. Estruturas são formalizáveis. Existe ciência em nossa prática. Quando defendem que a psicanálise não é uma ciência, arriscam reduzi-la a uma ideologia. Rejeitando a tese freudiana de que a psicanálise faz parte da Weltanshäuung (visão de mundo) científica, podemos mergulhar no obscurantismo, no relativismo absoluto ou na defesa pura e simples do interesse de cada um. O cenário social já se apresenta nos dias de hoje fragmentado em tribos que defendem por meio de uma ação social militante que seus integrantes seja tratados como exceção. Terminam por reforçar o liberalismo econômico, a supremacia da lei do mercado, o empuxo ao consumo e a prevalência do desmentido banalizado (Verleugnung) da função do Nome-do-Pai. O sujeito nos dias de hoje não é psicótico nem perverso, mas está muito mais liberado das amarras da tradição e se mostra frequentemente muito pouco capaz de sublimar suas pulsões. O mais importante para os fins desta conferência é argumentar que a vigorosa tese do psicanalista Jacques-Alain Miller de que o "Outro não existe", não é a que explica melhor a configuração de valores contemporânea. Ao 
contrário, penso que o grande Outro, a lei simbólica, a castração que divide o sujeito, são estruturas permanentemente confrontadas, recusadas e desmentidas. Defendo que se trata de pura radicalização histérica, rebelde a toda forma de autoridade, pronta a revelar que o "rei está nu". Parece que só existe satisfação quando transgredimos e ultrapassamos todos os limites. Como se o único desejo fosse o de ser tratado como exceção.

Uma vontade tão exacerbada de revolução pode indicar um desejo de encontrar um mestre muito mais forte. Freud (1921/1977) se refere ao fenômeno hipnótico que parece dominar as relações entre as massas e certos líderes. E Lacan (1969-1970/1991, p. 52), argumenta que ímpetos revolucionários conduzem ao ponto de partida, isto é, o reforço da função da mestria. Grande parte dos indivíduos rebeldes sonham, talvez, com um grande Outro muito mais poderoso. Lacan adverte que não se pode confundir a verdade analítica com a revolução. Reproduzo o comentário de Eric Hobsbawn (2015) acerca do livro de Hanna Arendt intitulado Sobre a revolução, na medida em que me parece coerente com as teses freudianas e lacanianas acerca deste tema. Embora este autor demonstre pouca confiança no método utilizado pela autora para extrair suas conclusões, me parece que ressalta a justeza de sua apreciação acerca do problema fundamental das revoluções:

Embora todas as experiências das revoluções passadas demonstrem, sem margem de dúvidas, que toda tentativa para resolver a questão social através de meios políticos leva ao terror, e que é o terror que as conduz à sua perdição, dificilmente se pode negar que evitar esse erro fatal é quase impossível quando uma revolução irrompe sob condições de pobreza generalizada. (Hobsbawn, 2015, p. 262)

Observo, não sem uma certa perplexidade, que o progresso da ciência, o liberalismo econômico e a implacável lei do mercado, além da expansão da democracia, podem dar lugar a ideologias políticas totalitárias. Em particular, destaco o crescimento tirânico do discurso politicamente correto que, a pretexto de defender os direitos daqueles que sofrem injúrias com o preconceito social, instalam uma vigilância paranoica contra supostos agressores e reivindicam indenização para todas as supostas vítimas. O medo de manifestar livremente sua opinião tem contribuído para engendrar uma maioria silenciosa que surpreende apoiando candidatos conservadores como Donald Trump. Em nome dos direitos de minorias excluídas, podem estar nascendo novas formas do grande Outro consistente muito mais opressivas do que a tradição, o Nome-do-Pai, a religião e a razão cientifica.

\section{O grande Outro é a razão?}

Vale recordar que a ambição de Freud foi, em seu tempo, a de exigir da razão científica um passo a mais, o reconhecimento da existência do inconsciente. A razão científica, se ela é mesmo racional, precisa admitir que os fenômenos inconscientes são a prova de que o homem é habitado 
pela fantasia, pelo sonho, isto é, pela realidade psíquica. Freud reafirma muitas vezes a tese, de que o "desamparo é a fonte de todos os motivos morais". O nascimento da moralidade é uma consequência do traumatismo do nascimento, momento inaugural em que o real se apresenta sem um grande Outro que Ihe de um sentido. Neste momento, o grito da criança é um significante solitário $\left(S_{1}\right)$. Não se articula ainda a ele nenhum Outro significante $\left(S_{2}\right)$ que possa interpretar seu significado.

Um ser humano por mais racional que ele pense que é, não poderá eliminar em sua subjetividade os restos, as marcas, as evidências e a pressão do profundo desamparo que causa seus desejos infantis de proteção. A necessidade de um pai protetor é também a fonte da religião. A ciência também surge da necessidade de superar o desamparo, apostando nos poderes da razão. Acreditar na razão é uma outra maneira de acreditar em Deus. Ciente da precariedade da razão diante da força primitiva do desamparo, Freud encarava suas teorias como hipóteses, que a experiência psicanalítica poderia, no futuro, retificar e até rejeitar. De fato, o único índice da veracidade da interpretação são seus efeitos sobre o sintoma. Na medida em que nossas intervenções alcançam deslocá-lo ou dissolvê-lo, acreditamos ter tocado em alguma coisa de real. Não é diferente do que se passa no campo da ciência, por maior que seja sua aspiração à exatidão. O real e a linguagem não são entidades homogêneas e para ler o que está escrito no grande livro da natureza é preciso traduzi-lo na linguagem da matemática. A veracidade de uma teoria científica também é essencialmente pragmática, depende de sua potência de inferir as supostas leis da natureza, e intervir sobre ela de modo eficaz. Dito de outro modo, tanto a psicanálise quanto a ciência restam suspeitas de habitarem, em última instância, o campo da magia.

Apesar do esforço que Freud fez para construir sua teoria da libido de acordo com os conhecimentos da física, da química e da biologia de seu tempo, não fazia da ciência uma ideologia cientificista. Ao contrário, o espírito da pesquisa freudiana extrai da ciência de sua época algumas metáforas e mantém aberto o diálogo com os saberes que fazem fronteira com a medicina. Acima de tudo, para não cair na ideologia, no misticismo ou na religião. À despeito do sucesso que a difusão da psicanálise conheceu em grande parte do mundo ocidental cristão, nem por isso Freud sonhava que sua invenção engendraria um novo discurso que não seria científico (Coelho dos Santos, 2012). E porquê? Porque, se o desamparo é a fonte de todos os motivos morais, não existe sujeito que não acredite em algum grande Outro. Não existe sujeito sem crença. A questão é: no que é que você acredita, pois o Outro sempre existe. E quanto ao psicanalista Jacques Lacan? São freudianas as principais definições lacanianas da verdade?

Recorto três proposições de Lacan (1998, p. 873) em "A ciência e a verdade". A primeira delas, e também a mais conhecida articula o nascimento do sujeito da psicanálise e o do sujeito da ciência: "o sujeito sobre quem operamos em psicanálise só pode ser o sujeito da ciência" (Lacan, 1998, p. 873). A segunda, destaca o preço a pagar pela liberdade que o sujeito da ciência conquistou em relação a saber da tradição: "Por nossa posição de sujeito somos sempre responsáveis" (Lacan, 
1998, p. 873) A terceira ressalta a diferença entre o homem, valor central em toda a metafísica humanista, e o sujeito sem particularidades da ciência: "não há ciência do homem porque o homem de ciência não existe, mas apenas seu sujeito" (Lacan, 1998, p. 873). O sujeito da ciência é o que Descartes promove quando revela que se "penso, logo existo". O sujeito da ciência não é uma evidência empírica. É deduzido do ato de pensar. E não pode haver pensamento racional, sem que o pensador acredite que Deus é lógico. Portanto, o sujeito sem qualidades empíricas, não se sustenta e não existe se o grande Outro da razão não atesta a legitimidade do passo de sentido que nos autoriza a deduzir que se penso... logo...existo. A ciência esvazia o homem, reduzindo-o ao sujeito, mas não dispensa a metafísica. Por esta razão, Freud (1933, p. 193-194) referiu-se ao desamparo do homem como a fonte de sua crença em Deus e no "super-homem idealizado" na figura do pai. $\mathrm{E}$ Lacan retomou este resto inesquecível quando afirma que a "psicanálise reintroduz na consideração científica o Nome-do-Pai". Eis aí o real, que nos obriga a não abrir mão de alguma coisa que é da ordem da crença.

Muitos anos depois, Lacan reafirma que o real da psicanálise coincide em parte ou mesmo inteiramente com o da ciência: "Suponham que se não houvesse nada de impossível no real - os cientistas fariam uma careta e nós também. Mas quanto caminho foi preciso percorrer para ver isso. Durante séculos acreditou-se que tudo era possível" (Lacan, 1974/2011, p. 16). O real não é o mundo. $O$ real não é o universal. $O$ real é a consequência lógica de uma verdade que é material: 0 significante (penso). A lógica se inaugura quando a sintaxe da língua natural é substituída pela fórmula (Penso, logo existo). Quando é que alguma coisa se apresenta como um real fora de sentido? Quando é impossível decidir se essa alguma coisa é verdadeira ou falsa. Neste caso, somente a fé no Outro da razão nos permite dar um passo lógico fundando o sentido.

A ciência e a psicanálise pressupõem o primado lógico desse real impossível. São o produto de um artifício da razão, uma criação a partir desse ponto - vazio de sentido - no universo infinito da ciência. $O$ campo da psicanálise funda-se num ato de fé na lógica. Freud atribuiu uma explicação a certos fenômenos sem sentido como o ato falho, o sonho, o sintoma. Enquanto fragmentos do real, é impossível saber se são verdadeiros ou falsos. Somente a crença no saber do grande Outro da razão pode reparar esta falha. É preciso acreditar no Outro que supostamente sabe o que isto quer dizer. O sujeito em si mesmo não tem substância alguma, mas a verdade não é ficção, mentira, invenção, equívoco vazia de real. A primeira teoria lacaniana é a de que a verdade é lógica. Se o real é impossível, a verdade não é apenas um fenômeno de superfície. Concordamos com Dany Dufour que existe uma razão no real. Mais Lacan não para por aí.

\section{O grande Outro é a lei do mercado?}

O segundo ensino de Lacan avança além da verdade lógica. O sujeito é dividido pelo significante e sua essência ou substância é somente lógica, mas o objeto com o qual ele se satisfaz é bem real. $O$ vazio de substância do sujeito é a causa lógica do desejo de saber. O saber sobre o 
inconsciente é de natureza simbólica, um tanto precário, efêmero, instável. O real é impossível, razão pela qual, o significante do Nome-do-Pai, alinhava com a crença na verdade, o sujeito a um Outro consistente. No segundo ensino de Lacan, o objeto acrescenta ao sujeito uma satisfação suplementar à verdade do inconsciente.

Lacan ensaia uma formalização de alguma coisa mais substancial que daria à verdade lógica um lastro real. Formaliza o objeto $a$, com base no conceito marxista de lucro ou mais valia. Esse conceito the permite articular o saber do grande Outro à verdade de cada um, demonstrando que a intersecção entre eles é o lucro, a satisfação pulsional. O objeto $a$, graças a sua estrutura topológica, é um resíduo, um furo, uma falha lógica que impede que o grande Outro seja completo. É preciso buscar isso que falta no corpo, por meio dos objetos que podem preenchê-lo. Se o grande Outro é Deus, não se pode acreditar nele cegamente. Pois a verdade não garante o ganho de gozo. Deus não pode ser apenas lógico, ele preciso assegurar o gozo. Graças ao objeto mais-de-gozar, Lacan reconfigura o sujeito do inconsciente à luz de uma teoria capitalista do mercado. Entre o sujeito e o Outro, não existe somente o desejo de saber. Existe o gosto pelo lucro.

Em seu livro intitulado $A$ arte de reduzir as cabeças, Dany Dufour ressalta que o mercado em sua forma atual abrange todas as atividades humanas. $O$ mercado é regulado pelo que Adam Smith chamou de "mão invisível". A lei do mercado também é Deus, se acreditamos que Deus também visa o lucro, o mais-de-gozar. O mercado é o novo Deus. Ele apregoa que cada um deve perseguir livremente a satisfação de seus interesses egoístas, pois deste modo, o interesse coletivo da sociedade será alcançado. Este milagre se produz graças à mão invisível que regula tudo, substituindo a Providência divina em suas obras. O mercado somente obedece à lei interna que busca escapar a todo controle externo. $\mathrm{E}$ que lei é essa? De acordo com o autor é a da produção de quantidades de mercadoria cada vez maiores, a custos cada vez menores. O mercado deve criar novos usos da mercadoria, chegando a passar para seu controle as esferas até então regidas por relações comunitárias, interpessoais, sexuais e geracionais.

Marx demonstrou que a força de trabalho entrou no mercado. Tornou-se uma mercadoria que se vende e se compra. Lacan observa que o saber também entrou no mercado, virou um diploma mercadoria. Tudo que era considerado sagrado pode se tornar mercadoria que se pode trocar, comprar, vender ou mesmo jogar fora. Passo a explorar o lugar que Lacan dá à tradição e à natureza na definição das identidades sexuais e que escapariam à lei do mercado. Ao final de seu ensino, observa-se que ele ainda faz da psicanálise uma prática à serviço de reintroduzir na consideração científica o Nome-do-Pai. Articula-o estreitamente à função do falo na parceria entre o homem, a mulher e a verdade.

\section{O grande Outro é a tradição?}

Na parceria sexual, o sujeito encontra o objeto causa de um mais-de-gozar, de um gozo suplementar. Para Lacan (1971/2006) não existe relação entre o homem e a mulher que não seja 
determinada pela castração. Basta consultar o Gênesis, pois encontraremos nas escrituras o corte operado pelo discurso: Deus os criou, homem e mulher. A castração da mulher é uma fantasia, pois é impossível castrá-la. Não há nada a castrar. A castração é a verdade do homem. Não é preciso que ele seja castrado na realidade para que se sinta ameaçado. $O$ real da castração é o mesmo real impossível em jogo no surgimento da lógica matemática. A castração é um dos nomes do real. A função do significante falo que orienta todo o campo do gozo sexual, serve para mascarar a realidade da castração. "É que para os homens, a menina é o falo e isso os castra. Para as mulheres, o menino é a mesma coisa, o falo, e é isso que as castra também, pois elas não alcançam senão o pênis, o que é um fracasso" (Lacan, 1971/2006, p. 25).

A mulher pode ter acesso ao pênis do homem. Mas o falo é alguma coisa que ora está ali, ora não está mais. O Nome-do-Pai é uma ficção que funda a diferença sexual enquanto tal. Deus os criou homem e mulher. A relação do homem e da mulher com esta ficção não é a mesma: "A mulher é a verdade do homem" (Lacan, 1971/2006, p. 34-35). É ela que pode dizer quanto ele vale, qual é o valor fálico. Essa diferença estrutural equivale a reafirmar que o fantasma, a verdade, a ficção não tem para um e para outro o mesmo estatuto. A mulher está muito mais próxima do real. $\mathrm{E} o$ que é a verdade? A verdade está no campo das fantasias que são construídas como defesa contra o real. Se o real é impossível e a verdade é efêmera, Lacan recorda que o livro sagrado, diferentemente, é um grande Outro. É o ato do criador quem funda a diferença entre os sexos: Eles os criou homem e mulher... Desiguais perante o real. Isso é, o que é. Não tem explicação.

Depois dos anos 1972/73, desde seu seminário Mais ainda, Lacan retorna ao assunto por meio das fórmulas da sexuação. Apresenta as duas vertentes da sexuação, a masculina e a feminina, afirmando que homens e mulheres podem situar-se seja numa vertente seja na outra. Esta perspectiva, que coincide inclusive com a tese freudiana exposta em um de seu últimos trabalhos, "O Ego e o Id". Freud (1923) nos apresenta o problema da sexuação como relativo à distinção entre a vertente da identificação e a vertente da escolha de objeto amoroso. Considera que o complexo de Édipo pode não ensejar apenas uma solução "positiva", ou seja aquela que leva a coincidência entre o sexo anatômico e a identificação sexuada. Alguns indivíduos podem identificar-se com alguém do sexo oposto e amar alguém do mesmo sexo. Trata-se da solução "negativa" do Complexo de Édipo. Freud, entretanto, não faz considerações acerca do mecanismo que conduz a uma inversão das relações de um sujeito com seu corpo anatômico (masculino ou feminino) e/ou com a nomeação simbólica que Ihe vem do Outro ao nascer (menino ou menina). Freud deixa em aberto uma discussão mais aprofundada acerca do mecanismo que leva alguém a desmentir seja a realidade imaginária do sexo anatômico, seja a nomeação simbólica que lhe veio do Outro. Também Lacan ao separar o sexo anatômico, a identificação sexuada e a escolha de objeto, enlaçados no discurso da tradição religiosa sob a égide do Nome-do-Pai, do falo e do objeto $a$, deixa em aberto uma questão essencial, porque alguns indivíduos revoltam-se contra a tradição. Porque alguns indivíduos desejam fazer uma revolução no campo da sexualidade? 
A inversão sexual esteve relacionada no início da obra freudiana (1914) com a perversão narcísica. Em 1910, analisa a homossexualidade de Leonardo da Vinci atribuindo-a à relação com a mãe. Em 1927 admite como explicação que a perversão fetichista possa ser a última barreira contra o homossexualismo. Neste caso estabelece uma vinculação mais clara com o desmentido da castração. Neste artigo, advogo que a radicalização da histeria, na contemporaneidade, pode coincidir com o desmentido das coordenadas imaginárias e simbólicas do discurso tradicional religioso que se desenvolve desde tempos imemoriais. Neste caso, trata-se de uma das dimensões do desmentido do Nome-do-Pai, em sua função de enlaçar os três registros. Este desmentido bastante comum desde os movimentos de maio de 1968 constitui-se como uma atitude fundamental de novos discursos sociais. É preciso pensar o tema da diversidade sexual à luz de uma discussão acerca do laço entre revolução sexual e radicalização histérica, abandonando outras vias que já explorei anteriormente e que levavam a uma leitura da sociedade contemporânea à luz da psicose ordinária.

\section{O grande Outro é político?}

Vivemos sob os efeitos liberalizantes e democráticos da Declaração Universal dos Direitos do Homem (1948). A igualdade e a liberdade entre os homens, entretanto, nunca reinam absolutas. A igualdade absoluta é impossível porque cada indivíduo é um sujeito do inconsciente e dá provas disso por meio de um sintoma, que é singular. As causas de uma doença orgânica podem ser as mesmas para todo mundo. A causa do sintoma psíquico não. Falar em diferenças naturais como se faz na bíblia, não é considerado politicamente correto. Dizer que o sintoma é singular também não. Os sintomas hoje se transformaram em causas políticas. Eles ensejam a formação de grupos que se organizam como movimentos sociais e reivindicam o respeito e a aceitação social. O que a militância política em defesa dos novos sintomas parece não levar em conta é que a vida sexual de cada um, em princípio, não deveria ser interessar demais a ninguém. Organizados em grupos reivindicativos, despertam muitas vezes o repúdio daqueles que consideram que tamanha exposição da vida privada é um tanto obscena. Cresce no seio de uma maioria silenciosa, o sentimento de que precisam defender seus valores e costumes ameaçados pela propaganda ostensiva da teoria da diversidade sexual. Uma onda conservadora pode ser, talvez, uma resposta aos avanços de uma mentalidade que não aceita nenhuma divergência.

O sintoma de um indivíduo é um resto de suas relações infantis com seus pais. Nesta relação ele não é sujeito, e sim um objeto desejado ou não. A ficção jurídica de que todos os homens nascem livres e iguais esquece que uma criança não é nunca livre e igual a um adulto. Os homens nascem pequenos, dependentes, e somente sobrevivem se o adulto os adota e cuida deles com amor. Uma criança, desejada ou indesejada, é sempre produto de uma relação entre um homem e uma mulher. Se toda criança tem origem no desejo de um homem por uma mulher, existe uma desigualdade que 
não podemos suprimir entre os seres humanos. Como bem demonstraram Freud e Lacan, os desejos entre homens e mulheres não são idênticos. Toda criança nasce numa família em particular.

Durante seus primeiros anos de vida, cada criança viverá na dependência de um pai e de uma mãe, tenha irmãos ou não. A mãe vai lhe dispensar um cuidado particular, pois seu amor por essa criança não é genérico. Não é a mesma coisa ser criado por sua mãe ou pela mãe do seu vizinho. $O$ pai, na medida em que escolhe uma mulher e faz dela seu objeto mais-de-gozar, transmite a cada um dos seus filhos uma lição sobre a causa do desejo. Essa lição contraria a ficção de que todos os homens são livres e iguais. O desejo de cada um não é igual ao de nenhum outro. O desejo de cada um distingue os homens entre si. Perante seu desejo, ninguém é livre. $O$ desejo nos determina, causa e impele.

Todo mundo pensa que um pai é o representante das normas e regras sociais. O pai não é um modelo genérico. Toda criança é marcada pela particularidade do modo pelo qual seu pai encarna essa função. $O$ que a maioria das pessoas não leva em conta é que é preciso - para aceitar as normas de comportamento civilizado e para aceitar ser tratado como igual a todo mundo - ter vivido a experiência de ser um sintoma para seus pais. É preciso ter feito a experiência de acrescentar alguma coisa que contribui para uni-los. A criança como sintoma de seus pais e o sintoma da criança são o modo pelo qual se enlaçam as pulsões e as exigências da civilização.

Os sintomas não se adaptam nunca completamente à civilização. Quando as crianças crescem e são submetidas às exigências coletivas dos processos educativos tornam-se mais parecidas com as outras crianças. Apesar disso, toda criança submetida ao processo educativo, distingue-se das demais por meio do seu sintoma. O sintoma é a prova da existência do inconsciente. Quando se chega à vida adulta não se elimina completamente o resíduo da dependência infantil. São dois aspectos fundamentais que persistem como modos de satisfação inconscientes: o modo particular como uma criança foi amada por sua mãe e, também, o modo pelo qual o pai exerceu sua função.

A liberdade e a igualdade são um ideal e não podem realizar-se completamente. Sonhamos com elas. Deveríamos tentar atingi-las oferecendo às crianças educação pública e gratuita. Entretanto, há um resto da ligação de cada criança ao seu contexto familiar que não pode ser eliminado. Isso é arcaico e irredutível. Precisamos desse arcaísmo para continuar gerando homens e mulheres capazes de transmitir a outros homens e mulheres o enigma da diferença sexual e da dissimetria entre as gerações. 0 enigma do sexo e da morte habita as profundezas do inconsciente. Por essa razão, não seremos jamais completamente modernos.

O discurso politicamente igualitário teve efeitos na redistribuição da sexuação, dissolvendo sua ancoragem na ideia de natureza. A anatomia não é mais "o destino" para alguns homens e algumas mulheres. Alguns indivíduos experimentam uma discordância entre a identidade simbólica (homem ou mulher) que o grande Outro da tradição Ihe atribui e o sexo anatômico - que eu defino como a percepção imaginária, mas também a experiência real do corpo. Ninguém nos dias de hoje 
é considerado um psicótico porque não acredita no nome simbólico (menino ou menina) que seu corpo recebeu do grande Outro, menino ou menina. Um homem pode não dar ao seu órgão genital um valor sexual. Pode decidir retirá-lo se atrapalha seu sonho de ser uma mulher. $O$ fato de ter uma vagina e um útero pode não significar absolutamente nada para uma mulher que quer ser um homem. Eles não fazem a menor questão de imitar a natureza!

Entretanto, a vontade de se rebelar não cessa de produzir novas reivindicações. Muitos homossexuais atualmente querem se casar e ter filhos imitando os heterossexuais que acreditam na natureza. A luta pelo direito de todos ao casamento civil mostra que o movimento gay não reivindica mais o direito de ser tratado como exceção à norma heterossexual. Nos anos 1970, o discurso gay recusava o sonho naturalista de felicidade familiar com seus papéis tradicionais: marido, mulher, papai, mamãe, bebês. O movimento gay representava o máximo de oposição à tradição. Ao longo dos anos, este discurso não foi capaz de produzir novos papéis sociais. O discurso gay contemporâneo defende que se pode casar dois maridos ou duas esposas e ter filhos com papaipapai e mamãe-mamãe. Desejam que os papéis sociais inventados pelos que acreditam na bíblia, na natureza, sirvam para vestir todo mundo. Não é muito estranho tudo isso? A única coisa que triunfa em nossos dias, aparentemente, é a vontade dos antigos rebeldes de ser igual a todo mundo. Não seria este um belo exemplo de que a vontade de revolução reconduz ao ponto de partida? Estamos de volta á universalização da organização familiar como única manifestação do amor, do desejo e da sexualidade.

O desejo de ter filhos distancia-se das práticas heterossexuais de reprodução natural. 0 progresso das tecnologias de reprodução assistida tornou desnecessário que este desejo se submeta às atribulações do ato sexual para obter sua satisfação. Casais assexuados, homossexuais, transgêneros, podem valer-se das novas tecnologias para produzir um bebê. Graças a estes procedimentos a noção de família humana está em vias de ser profundamente redefinida. $O$ que dizer, então, dos significantes homem e mulher, pai e mãe? O que significarão ao longo do século XXI?

Por que considero que esta questão é essencial para as relações entre o campo da psicanálise e a política? Porque nos assombramos com a facilidade com que os políticos mentem, enganam, manipulam cinicamente as aspirações e crenças de seus eleitores. Que valor têm honestidade intelectual e ética nas relações com os outros, quando a lei do mercado reduz a tudo e a todos ao objeto mercadoria que se compra, se vende e se troca? Quando nada mais é considerado sagrado e insubstituível? Que valor nós concedemos à honestidade intelectual e a ética na relação com os outros quando defendemos o direito ilimitado e democrático de cada um definir-se a si mesmo, sem levar em conta o que lhe foi transmitido pelos seus pais e professores? O direito de reinventar-se, o direito de criar realidades paralelas e fantasiosas e o direito de vendê-las a quem quer comprar não pode ser criminalizado, nem regulamentado. Quando a lei do mercado e a propaganda política conquistam espaço contra a tradição e a razão, tudo parece conduzir a uma única lei: a cada um 
seu grande Outro. A verdade pode ser inventada, desmentida e substituída por novas ficções. Na era da pós-verdade todo fato não passa de uma versão ou uma ficção.

Esta aparente pluralização do grande Outro não oculta completamente a necessidade soberana de obediência à lei do desamparo, nome freudiano do real lacaniano. O desejo revolucionário fracassa em nos libertar da dimensão não eliminável do real. Não existe sujeito sem crença. Não há sujeito que dispense a dimensão da verdade. O mais difícil é conciliar a verdade de cada um com o a verdade dos outros, da maioria. Refugiar-se em tribos ou em guetos minoritários pode conduzir a novos totalitarismos ou discursos políticos identitários. Se não há relação sexual, mesmo assim é preciso instituir algum consenso que valha para todos. A dimensão da crença no universal não desaparece no universo infinito da ciência. Quanta honestidade intelectual é preciso para reconhecê-lo?

\section{Notas:}

${ }^{1}$ Baseado na conferência de encerramento ao VI Simpósio do ISEPOL, realizado nos dias 30/09 e 01/10/2016.

${ }^{2}$ No original: "Then came the Internet. The era of the fact is coming to an end: the place once held by "facts" is being taken over by "data." This is making for more epistemological mayhem, not least because the collection and weighing of facts require investigation, discernment, and judgment, while the collection and analysis of data are outsourced to machines. "Most knowing now is Googleknowing—knowledge acquired online," Lynch writes in "The Internet of Us" (his title is a riff on the ballyhooed and bewildering "Internet of Things"). We now only rarely discover facts, Lynch observes; instead, we download them. Of course, we also upload them: with each click and keystroke, we hack off tiny bits of ourselves and glom them on to a data Leviathan".

${ }^{3}$ Disponível em https://eleitornews.blogspot.com/2016/09/lula-compara-servidores-publicos.html (acesso em 30/10/2016).

\section{Referências Bibliográficas}

Carranca, A. (2016). A era da mentira - confiança excessiva no que a internet oferece prejudica percepção da verdade. Recuperado de http://oglobo.globo.com/mundo/a-era-da-mentira18914609.

Coelho dos Santos, T. (2001). Quem precisa de análise hoje? São Paulo: Bertrand Brasil.

Coelho dos Santos, T. (2008). Finais de análise: sexuação e invenção. Tempo psicanalítico, (40), 105-120. Rio de Janeiro: SPID.

Coelho dos Santos, T. (2008). Entre tapas e beijos: sobre a vacilação de semblantes da diferença sexual. Latusa - Revista da Escola Brasileira de Psicanálise - Seção Rio de Janeiro, (13). Rio de Janeiro: EBP. 
Coelho dos Santos, T. (2008). Ciência e clínica psicanalítica: sobre o estruturalismo. Estudos Lacanianos, 1(1), 187-199. Recuperado de http://pepsic.bvsalud.org/pdf/rel/v1n1/v1n1a16.pdf.

Coelho dos Santos, T. (2009). Sinthoma: a arte de encarnar e sublimar o próprio sexo. In Coutinho Jorge, M. A. e Mello de Lima, M. (Orgs.). Saber fazer com o real: diálogos entre Psicanálise e Arte. Rio de Janeiro: Companhia de Freud, PGPSA/IP/UERJ.

Coelho dos Santos, T. (2009). Não existe pecado do lado de baixo do equador? Cadernos de Psicanálise, 25(28), 121-142. Rio de Janeiro: Sociedade de Psicanálise da Cidade do Rio de Janeiro.

Coelho dos Santos, T. (2009). Semblante e discurso: estrutura e verdade na ciência e na psicanálise. Latusa - Revista da Escola Brasileira de Psicanálise - Seção Rio de Janeiro, (14). Rio de Janeiro: EBP.

Coelho dos Santos, T. (2009). A interpretação analítica do sinthoma. In Nascimento, E. (Org.). Revista do Curso de Especialização da UFBA (pp. 161-175). Salvador.

Coelho dos Santos, T. (2009). Sobre a clínica de orientação lacaniana: dos impasses da sexuação à invenção do parceiro-sinthoma. Ágora, (12), 9-26. Rio de Janeiro: PPGTP/UFRJ.

Coelho dos Santos, T. (2010, out.). Lá onde o inconsciente falassério, o real morre de rir. Opção Lacaniana - Revista Brasileira Internacional de Psicanálise, (58), 147-159. São Paulo: Eólia.

Coelho dos Santos, T. (2010, nov. a 2011, abr.). A dimensão real da inserção na ordem simbólica. aSEPHallus - Revista Eletrônica do Núcleo Sephora, 6(11), 1-17. Recuperado de: http://www.isepol.com/asephallus/numero 11/artigo 01 revista11.html.

Coelho dos Santos, T. (2011). A materialidade da letra e o realismo da estrutura na psicanálise de orientação lacaniana. In Lo Bianco, C. (Org.). A materialidade da psicanálise. Rio de Janeiro: Contracapa.

Coelho dos Santos, T. (2011, nov. a 2012, abr.). Sobre o real sem sentido nas ciências em geral e na psicanálise em particular. aSEPHallus - Revista Eletrônica do Núcleo Sephora, 7(13). Recuperado de http://www.isepol.com/asephallus/numero 13/artigo 01.html.

Coelho dos Santos, T. (2012, mai. a out.). O lugar certo onde colocar o desejo do analista na era dos direitos. aSEPHallus - Revista Eletrônica do Núcleo Sephora, 714). Recuperado de http://www.isepol.com/asephallus/numero 14/artigo 01.html.

Coelho dos Santos, T. (2012). Existe uma nova doutrina da ciência na psicanálise de orientação lacaniana? In Coelho dos Santos, T.; Martello, A. \& Santiago, J. (Orgs.). De que real se trata na clínica psicanalítica? Psicanálise, ciência e discursos da ciência (pp. 35-61). Rio de Janeiro: Cia de Freud.

Freud, S. (1976). Psicologia de grupo e análise do ego. In J. Salomão (Trad.). Edição Standard Brasileira das Obras Psicológicas Completas de Sigmund Freud (Vol. 21, pp. 91-184). Rio de Janeiro: Imago (Trabalho original publicado em 1921). 
Freud, S. (1976). A dissolução do complexo de Édipo. In J. Salomão (Trad.). Edição Standard Brasileira das Obras Psicológicas Completas de Sigmund Freud (Vol. 19, pp. 215-226). Rio de Janeiro: Imago (Trabalho original publicado em 1924).

Freud, S. (1976). Sexualidade Feminina. In J. Salomão (Trad.). Edição Standard Brasileira das Obras

Psicológicas Completas de Sigmund Freud (Vol. 21, pp. 257-281). Rio de Janeiro: Imago (Trabalho original publicado em 1931).

Freud, S. (1976). Feminilidade. In J. Salomão (Trad.). Edição Standard Brasileira das Obras Psicológicas Completas de Sigmund Freud (Vol. 22, pp. 130-165). Rio de Janeiro: Imago (Trabalho original publicado em 1933).

Freud, S. (1976). A organização genital da libido. In J. Salomão (Trad.). Edição Standard Brasileira das Obras Psicológicas Completas de Sigmund Freud (Vol. 19, pp. 177-186). Rio de Janeiro: Imago (Trabalho original publicado em 1923).

Freud, S. (1976). Algumas consequências psíquicas da distinção anatômica entre os sexos. In J. Salomão (Trad.). Edição Standard Brasileira das Obras Psicológicas Completas de Sigmund Freud (Vol. 19, pp. 303-322). Rio de Janeiro: Imago (Trabalho original publicado em 1925).

Freud, S. (1976). Mal-estar na civilização. In J. Salomão (Trad.). Edição Standard Brasileira das Obras Psicológicas Completas de Sigmund Freud (Vol. 21, pp. 81-178). Rio de Janeiro: Imago (Trabalho original publicado em 1930[1929]).

Freud, S. (1976). A análise terminável e interminável. In J. Salomão (Trad.). Edição Standard Brasileira das Obras Psicológicas Completas de Sigmund Freud (Vol. 23, pp. 239-287). Rio de Janeiro: Imago (Trabalho original publicado em 1937).

Hobsbawn, E. (2015). Revolucionários: ensaios contemporâneos. São Paulo: Paz e Terra.

Keys, R. (2004). The post-truth era: deshonesty and deception in contemporary life. New York: St. Martin's.

Lacan, J. (1954-1955/1978). Le séminaire, livre II: le moi dans la théorie de Freud et dans la technique de la psychanalyse. Paris: Seuil.

Lacan, J. (1959-1960/1986). Le séminaire, livre VII: l'éthique de la psychanalyse. Paris: Seuil. Lacan, J. (1963/1966). Kant avec Sade. Écrits (pp. 765-792). Paris: Norton.

Lacan, J. (1965-1966/ 1966). La science et la verité. Écrits (pp. 855-878). Paris: Norton. Lacan, J. (1968-1969/2006). Le séminaire, livre XVI: d'un Autre à l'autre. Paris: Seuil. Lacan, J. (1969-1970/1991). Le séminaire, livre XVII: l'envers de la psychanalyse. Paris: Seuil. Lacan, J. (1971/2006). Le séminaire, livre XVIII: d'um discours qui ne serait pas du semblant. Paris: Seuil.

Lacan, J. (1972-1973/1984). Le séminaire, livre XX: encore. Paris: Seuil. Lacan, J. (1975-1976/2005). Le séminaire, livre XXIII: le sinthome. Paris: Seuil. Latgé, L. C. (2016, nov.). O mundo pós-verdade. O Globo. Recuperado de http://noblat.oglobo.globo.com/geral/noticia/2016/11/o-mundo-pos-verdade.html. 
Lepore, J. (2016, mar.). After the Fact - In the history of truth, a new chapter begins. Recuperado de http://www.newyorker.com/magazine/2016/03/21/the-internet-of-us-and-the-end-of-facts.

Machado, A. M. (2016, set.). Transparência e encenação. O Globo. Recuperado de http://noblat.oglobo.globo.com/geral/noticia/2016/09/transparencia-e-encenacao.html.

Murad, R. (18/09/2016, set.). Como ela é... O Globo. Recuperado de http://noblat.oglobo.globo.com/geral/noticia/2016/09/como-ela-e.html.

Padilha, J. (2016, ago.). Lula e Trump. $O$ Globo. Recuperado de http://noblat.oglobo.globo.com/geral/noticia/2016/08/lula-e-trump.html.

Padilha, J. (2016, set.). Black blocs e desonestidade intellectual. Recuperado de http://noblat.oglobo.globo.com/geral/noticia/2016/09/black-blocs-e-desonestidadeintelectual.html.

Trump, D. J. \& Schwartz, T. (1988). Trump: a arte da negociação. Rio de Janeiro: Campus.

Citacão/Citation: Coelho dos Santos, T. (mai. a out. 2016). Desmentido ou inexistência do Outro: a era da pós-verdade. Revista aSEPHallus de Orientação Lacaniana, 11(22), 4-19. Disponível em www.isepol.com/asephallus. doi: 10.17852/1809-709x.2019v11n22p04-19.

Editor do artigo: Tania Coelho dos Santos.

Recebido/Received: 02/05/2016 / 05/02/2016.

Aceito/Accepted: 18/05/2016 / 05/18/2016.

Copyright: () 2013 Associação Núcleo Sephora de Pesquisa sobre o moderno e o contemporâneo. Este é um artigo de livre acesso, que permite uso irrestrito, distribuição e reprodução em qualquer meio, desde que o autor e a fonte sejam citados/This is an open-access article, which permites unrestricted use, distribution, and reproduction in any medium, provided the author and source are credited. 